\title{
ENTRE PARÁSITOS Y AUSENTES. PASEO FIGURATIVO POR EL CAMPO (INTELECTUAL) LATINOAMERICANO
}

\section{Among parasites and absents. A figurative walk through the Latin American (intellectual) field}

\author{
Gabriel Gatti* \\ * Universidad del País Vasco / Euskal Herriko Unibertsitatea \\ g.gatti@ehu.eus
}

Palabras clave

paisaje

habitable

desaparecidos

parásito

América Latina

Keywords unhabitable landscape disappeared parasite Latin America

\begin{abstract}
Resumen
Este texto desarrolla una sociología figurativa algo primaria sobre una posición concreta dentro del universo de los "investigadores e intelectuales latinoamericanos": la que se define a partir de mis zapatos. No es solo por un ejercicio de egolatría incontenida, ni por una apuesta de estilo frente a los grandes cuadros sociológicos; no es lo primero, porque la primera persona es lo que se pidió para este texto. No es lo segundo porque de esos cuadros este trabajo no es una alternativa, es un complemento. $Y$ si es como es, es porque no encuentro otra salida que esa para analizar las posiciones biográfico-intelectuales de los investigadores latinoamericanos fuera de América Latina. Aunque sé que existe ese objeto y sé que lo habito, es demasiado inconsistente para mapearlo con demasiada dureza; lo haré entonces con suavidad, con tres conceptos nacidos de mi propia condición de latinoamericano fuera de América Latina: parásito, desaparecido y paisaje habitable.
\end{abstract}

\section{Abstract}

This text develops a somewhat basic figurative sociology regarding a concrete position within the universe of "Latin American researchers and intellectuals": the position that is defined from my shoes. It is not merely an exercise in unrestrained egomania, nor a different stylistic approach with respect to major sociological frameworks. It is not the former because a first person perspective was precisely what was requested for this text. It is not the latter because this work is not meant as an alternative to those frameworks but as complementary. And if it is how it is, it is because I find no other way to analyze the biographical-intellectual positions of Latin American researchers outside Latin America. Although I know that that object exists and I know that I inhabit it, it is too inconsistent to map it too severely; I will tread gently, then, drawing on three concepts born from my own condition as Latin American outside Latin America: parasite, disappeared, and inhabitable landscape

Gatti, G., 2015, "Entre parásitos y ausentes. Paseo figurativo por el campo (intelectual) latinoamericano", en Papeles del CEIC, vol. 2015/1, no 115, CEIC (Centro de Estudios sobre la Identidad Colectiva), Universidad del País Vasco, http://dx.doi.org/10.1387/pceic. 13066 
"En principe, je fais partie de ce groupe si malade, à qui aujourd'hui je donne la parole et que je représente" (Serres, 1996: 22)

\section{ANTES MUERTO QUE SENCILLO}

El motivo de este número monográfico de Papeles del CEIC, sus tópicos, invita a localizar el propio cuerpo en un gran cuadro. Por lo primero no hay problema: no me resulta problemático hablar en primera persona, ni tener que mostrar(me) haciendo mi trabajo. A fin de cuentas formo parte de una generación de científicos sociales que si no en todo sí que en parte hemos incorporado aquello de la "objetividad situada" (Haraway, 1995) como una de sus máximas, y que ejerce sin demasiado pudor la convicción no ya de que cuando se habla del mundo se habla en realidad de uno, sino de que cuando se habla de uno se habla en realidad del mundo. Sí que sin embargo me resulta problemático hacer un gran cuadro. Quizás sea esa la exigencia del oficio, quizás quepa construirlo sea cual sea el caso o el objeto del que se hable. Reconozco el valor cartográfico de esos cuadros, su utilidad intelectual. y hasta política. Para el caso y para el objeto es sin duda preciso hacer una cartografía de las posiciones biográfico-intelectuales de los investigadores latinoamericanos y situar en ella las vidas de aquellos que son/somos eso desde fuera de América Latina. Tan preciso es que para eso se organiza este número de Papeles del CEIC: la idea de intelectual o de investigador latinoamericano no es nueva, y es claro que las cosas han cambiado. Tiempo atrás un mapa del asunto debería reflejar movimientos de entradas y salidas sencillos en el lugar que da sentido al topónimo de tales intelectuales e investigadores, América Latina: se era, se salía, se regresaba. Más o menos. Pero ese movimiento ha cambiado sustancialmente y lleva tiempo sin hacerse un aggiornamento del estado de la cuestión en la materia. Toca mandar de nuevo a los geógrafos y a los sociólogos al terreno; y tienen trabajo.

No obstante eso, quisiera trabajar de una manera distinta. El deseo de distinción nace, en parte, de una apuesta de estilo, más sensible a otro tipo de ejercicios, inclinado a una suerte de sociología entre impresionista y figurativa, en el sentido más literal que se le quiera dar a eso: pinturas, emociones, figuras de personajes que campean por terrenos ya más o menos conformados; sociología de sujetos que administran realidades que les vienen dadas. Pero hay algo más que esa apuesta: intuyo que el caso, que el objeto que nos ocupa, sea porque está naciendo, sea porque es esa su condición, se llevará mal con cualquier esfuerzo de cartografiado. En su conformación presente, "posiciones biográfico-intelectuales de los investigadores latinoamericanos" es un objeto demasiado disperso como para legitimar ese ejercicio. Mis reticencias frente a un trabajo de mapeado clásico, 
entonces, no pasan solo por una cuestión de método en época de conocimientos situados y de fragilidad de los grandes cuadros o de estilo dentro de una apuesta por una especie de sociología impresionista y pictográfica. Estando esos asuntos en el horizonte de este trabajo, también está que francamente no creo que para hacer sociología de lo que nos ocupa, algo decidida y necesariamente móvil, quepa otra cosa que esa cuestión y esa apuesta.

Comienzo pues. Hablaré desde mis zapatos, zapatos en los que para el caso se superponen varias capas de betún: el nacimiento en América Latina, en Uruguay, la formación en Europa, en Madrid, el trabajo y con plaza de funcionario en Europa, en el País Vasco, en un lugar (el Centro de Estudios sobre la Identidad Colectiva) desde donde investigo sobre identidad alli donde tenga sentido hablar de ese tema, y donde muchas de mis inquietudes se orientan a pensar cosas que ocurren tanto allí como aquí — siendo la ambigüedad de los adverbios parte de la gracia de mi juego: vale uno tanto para América Latina como para Europa, vale el otro tanto para Europa como para América Latina-. Con todo eso, ni yo ni mis zapatos nos hallamos cuando nos queremos situar en los tipos ideales que se nos ofrecen de latinoamericanos trabajando fuera (de América Latina) sobre el dentro (de América Latina). A lo sumo me reconozco en alguno de los bordes de esos tipos: formado en el exterior, emigrante, foráneo... (véase el texto de Danilo Martuccelli, 2015, en este número de Papeles del CEIC). Siempre ocurre, es cierto; nadie ni el más ideal de los tipos, es un tipo ideal. Siempre ocurre, también es cierto, que una sociología de grandes cuadros se complementa con otra más figurativa. Bien, mejor. Intentaré hacer algo de esta última entonces para acompañar a los que en este número han apostado por la primera estrategia.

Lo haré proponiendo categorías surgidas de mi propia experiencia de investigación. Serán tres: la de parásito, la de desaparecido, la de paisaje habitable. Es una forma poco elegante de cumplir con los dos mandatos de este número monográfico: hablar del campo y hablar de la biografía intelectual de los investigadores que lo habitan, todos los invitados a escribir en él, a partir del propio aparataje. Las tres categorías son partos de mi experiencia vital y profesional pero al tiempo que eso, herramientas posibles para pensar esa experiencia vital y profesional; o eso quisiera. Pensar lo que nos ocupa en este número de Papeles del CEIC como un paisaje habitado de parásitos y de desaparecidos, más que como un territorio firme lleno de personajes recios, se me hace no solo más cordial o más familiar, sino más acertado empíricamente. Al menos desde la empiria que mis zapatos recorren, bien cortita; es ésa en cualquier caso la apuesta de este pequeño ejercicio de sociología 
impresionista y figurativa que les propongo. Que nadie se ofenda; no es sino un divertimento serio.

\section{PARÁSITOS CON MAL ACENTO DISIMULANDO MARCAS}

Y en el origen, el desembarco en tierras ajenas y la evidencia de la distancia entre las orillas.

Soy, es claro, investigador latinoamericano no residente en América Latina: nací allí, y vivo y trabajo en el exterior de América Latina aunque entre las cosas que hago muchas se materializan alli, en América Latina. Soy parte, no lo dudo, del grupo al que convoca este número pero no integro, o eso creo, sus líneas centrales: vine muy joven a Europa, en lo académico soy netamente europeo (aunque a veces - pocas pero importantes - colegas locales poco dados al viaje me recuerden lo contrario y el estigma del foráneo, si conviene, me marca), hablo español con acento más madrileño que montevideano. No sé por dónde empezar... de dónde. El lugar es la cosa. Mi lugar. Cuando era adolescente jugaba con mi doble nacionalidad (español y uruguayo - e italiano, pero esas es otra historia, más circunstancial-) sufijándola y llenándola de signos que acotasen todo lo que una nacionalidad, aunque sea doble o triple, afirma sobre quien la porta: hispa-NO!/urugua-YO? Con el tiempo, tomé mis decisiones para simplificar ese gentilicio tan monstruoso, entre ellas trabajar sobre el asunto, la identidad, que me preocupaba. La decisión no fue solución, pero no fue mala; permitió explorar posiciones de identidad desajustadas y trabajar algunos conceptos duros (Gatti, 2007), de los que solo daré cuenta de uno, el de parásito.

En Atlas, un libro impresionante, Michel Serres escribió: "La filosofía sólo ha explorado, pobremente, el sobre, para la trascendencia, el bajo para la sustancia y el sujeto, el dentro para el mundo y el yo inmanentes. ¿Hay que generalizar más? Continuará con el con de las comunicaciones y del contrato, con el a través de la traducción, el entre de las interferencias, el por de los pasos por donde pasa Hermes y pasa un ángel, el cabe del parásito, el fuera del desapego... todas las variedades espaciotemporales que nos ofrecen todas las preposiciones, declinaciones o flexiones" (1995: 80). A la sociología de la identidad le ha pasado, históricamente, lo mismo, o peor: su régimen preposicional es, apenas, el del dentro y el fuera y últimamente el a través y el entre (emigraciones, diásporas, hibridaciones). Me interesa el cabe del parásito.

El parásito no construye identidad, trabaja disponiéndose ante identidades ya producidas, desplazándose por nombres y patrimonios ajenos y asentados. Vive incómodo, pues está fuera de sí, pero vive. En ciencias sociales hemos pensado mucho sobre los anfitriones, pero poco 
sobre los parásitos. Algo hay, sin embargo, sobre algunos de los que como él residen en los entre-dos de regiones estables: extranjeros, forasteros, emigrantes, exiliados... Ni de dentro ni de fuera: "no están en la sociedad pero no están tampoco más allá, en otro tipo de sociedad ideal" (Sansot, 1993: 163). Los forasteros son, de esa nómina, los personajes que la sociología ha trabajado más. Por las huellas que quedan de su origen, por los restos que mantienen de su herencia, los forasteros son entidades manifiestamente outsiders; por su deseo de integración, por las tácticas que emplean para alcanzar la pertenencia de pleno derecho, los forasteros comparten con el grupo de acogida experiencias y referencias. La suya es, pues, una vida entre paréntesis (Vásquez, 1987: 31), a medio camino entre la pertenencia y el extravío. Mestizo mixtura extranjero, híbrido son algunos de los términos a los que se acude para pensarlo desde la sociología de la identidad, siempre muy prolífica en lo que a los adjetivos se refiere. Todos ellos son buenos para representar el equilibrio inestable, útiles para pensar en personajes que aunque claros en la localización de los extremos entre los que pivotan, no pueden nunca detener con un tercer término su identidad, siempre en baile.

Así es: la preposición entre y la conjunción y son sus locuciones preferidas: uruguayo y español, vasco y español, entre dos mundos... Sobre un grupo de ellos construí mi tesis doctoral (Gatti, 2007): gentes que habitando en el lugar (el País Vasco) lo administraban desde una posición de cierta exterioridad y construían sentido en mundos de vida - los constituidos en torno a los momentos y lugares del aprendizaje de euskera por adultos - con fuertes marcas de indefinición. Eran y son mundos marcados por sus dependencias de los lugares de origen y de los de llegada ( $n i$ español ni vasco, ni en euskera ni en castellano...). Espacios medios, fronterizos, convertidos en territorio de sujetos del entre y del cabe: y... y, ni... ni, seres que se hacen dentro de otros seres; mejor de otros Seres. Uno y otro; entre uno y otro. "Se es una cosa y, al mismo tiempo, otra cosa; se está integrado a la sociedad pero, al mismo tiempo, no se está completamente integrado" (Barel, 1984: 43). El forastero como atopos, no-lugar, figura social desprovista de lugar apropiado en el espacio social y de lugar asignado en las clasificaciones sociales (Santamaría, 1994: 65-66). Así: aquellos, entre vascoparlantes y castellanoparlantes. Estos, los que ahora nos ocupan, entre latinoamericanos y europeos. Los unos y los otros hechos dentro de universos ya constituidos, de los que beben, a los que habitan. Parásitos, quizás, es otro adjetivo posible para su régimen de identidad.

Alfred Schütz (1974: 95-107) supo entender las dificultades de la situación en la que se encuentra un forastero cuando emprende el acercamiento a las rutinas de conocimiento y de clasificación de la 
comunidad que le acoge y debe gestionar su incómoda posición. Pues, en efecto, solamente después de "haber reunido cierto conocimiento de la (...) nueva pauta cultural, puede el forastero comenzar a adoptarla como esquema de su propia expresión" (ibídem: 102-103). Mientras, se mueve inseguro, dubitativo, tartamudeando, sin la seguridad de la que pueden hacer gala los que manejan las recetas, sino con la vacilación propia del que las está investigando. Es el hombre "que debe cuestionar casi todo" (ibídem: 100), y es, por eso, un ser tan sospechoso como objetivo. Resulta, primero, sospechoso, pues su fidelidad está en duda, tanto para los que abandona, aquellos que quedan en la "parrilla de salida" del recorrido, como para los que le acogen, los que le esperan en la meta de la trayectoria que les conduce a ser parte de un nuevo nombre. Se duda, en efecto, de su lealtad, pues no siempre el forastero quiere o puede sustituir totalmente la pauta cultural de su grupo de origen por la nueva pauta cultural. Razón ésta de la objetividad del forastero. No se interprete mal: no se quiere decir que el forastero sepa más o sepa mejor, sino que está en la obligación de saber; esto es, de objetivar para conocer eso a lo que debe o desea incorporarse, de singularizarlo, de reducirlo a sus rasgos más sustantivos; en suma, obligado a objetivar, para pensarlas, las entidades entre las que se desplaza. Obligado, en fin, a tematizar la identidad como objeto, el forastero mira cómo se habla y disimula, naturaliza su acento, esto es: hace del acento ajeno su acento, pero es una naturaleza pensada ("el tratamiento del idioma que se impone (...) fuera de contexto y a menudo en situaciones de simulación, es de naturaleza metalingüística y obliga a recurrir a la conciencia" (Trévise, 1993: 43)).

Le pasa esto al castellanoparlante que aprende euskera, también al investigador latinoamericano fuera de contexto, tanto cuando habla de un lado del océano como cuando lo hace del otro. No puede desprenderse de sus marcas: el acento, el estilo, los modismos. En sus contribuciones a este monográfico Danilo Martuccelli (2015) y Denis Merklen (2015) problematizan la cuestión de la lengua y piensan acerca del peso que tiene hablar y escribir en una distinta a la propia -si por tal se entiende la de nacimiento- en la producción intelectual de quien trabaja fuera: tiene que decidir en qué produce, en qué piensa, para quién destina lo que hace y lo que piensa. Y en general tiene que bifurcarse, sabiendo que la bifurcación supone pérdidas, en cantidad y en calidad.

¿A quién afecta esto? A todo bilingüe. Pero ¿qué es un bilingüe? ¿Uno que habla dos lenguas? No: uno que habita en el tránsito entre ellas, a las que habita sin que sean, sin embargo, propias. Solo está cómodo en las traducciones. Así es: para el bilingüe, el asunto no es tanto emplear bien la lengua de cada una de las dos orillas que le definen, ni siquiera el 
traducir bien, sin mácula, de una a otra y de otra a una; el asunto está en cómo administrar su vida en los pliegues del diccionario (Serres, 1996: 26) ${ }^{1}$, único lugar que para él es confortable. Su acento siempre le delata, y eso crea distancias y solidaridades poderosas: participa de fratrias (las de los de acentos de otros y sobre las de los hermanados por tener acentos otros, los sudacas fuera de América Latina solidarizados por su no-acento local compartido) que en origen no se constituirían; se diferencia de locales de los que no debería. Y cuando se encuentra solo, hace esfuerzos de camuflaje de la diferencia que, sin duda, dejan huella en su cuerpo. Entiéndase que hablo de lenguas en un sentido amplio, que incluye acentos y modismos, que se refiere a marcas en el habla más que a idiomas. Afecta tanto a los que viven y trabajan en lugares de lenguas im-propias (Francia, Alemania, Brasil, Inglaterra, Estados Unidos) como a quienes trabajamos en la misma lengua que la propia (en España, México, País Vasco, Perú...). El esfuerzo del parásito es, para el caso, parecido en uno y otro espacios. El bilingüe es el que siempre está fuera; el parásito está siempre fuera de sí, siempre en casa de otro. Hispa-NO!/urugua-YO? No estaba tan errado. El lugar a pensar eran las barras, los guiones, los interrogantes, no lo que eso une y separa.

\section{UN DESCANSO ENTRE BICHOS Y MONSTRUOS}

Y un hueco en el relato². Un momento tranquilo, o más que eso, de asentamiento: Ia tesis Ilega (2002), los concursos y los puestos le siguen (a partir del 1993 en condiciones precarias, de 2002 en adelante ya no). El parásito se aloja bien adentro en la carne del huésped. Se hace huésped. Aloja a otros: obtiene plaza propia y definitiva (en 2009) -le cuesta, como a todos, pero la obtiene-. Se hace dueño del sitio. Tiene una hija y aunque participa de la idea de ponerle nombre de pájaro viajero es uno más del lugar.

Y es ahi que se descubre latinoamericano y desaparecido: hacia el año 2000, por serendipidades que no vienen al caso, pero que ligan las identidades débiles de algunos vascos, con la vida social invisible de Yves Barel, con los lectores de la bibliografía -tan en boga- de ciertos feminismos, con los desaparecidos argentinos,

\footnotetext{
${ }^{1}$ La frase, hermosa, de Michel Serres merece ser reproducida íntegramente y en versión original: "Le pensez-vous simple? Non, bien sûr, double (...). Bilingue ne veut pas dire seulement qu'il parle deux langues: il passe sans cesse par le pli du dictionnaire (...). Vous ne tenez pas compte du passage, de la souffrance, du courage de l'apprentissage (...). Vous le croyez double (...) et le voilà triple ou tiers, habitant les deux rives et hantant le milieu où convergent les deux sens".

2 Cuyo hallazgo debo a uno de los evaluadores, al que agradezco su lectura en profundidad y su intuición.
} 
alguien al que el parásito no conocía usa una idea (lo social invisible) que fue pensada para una cosa (vascos en posición parasita) para pensar otra (desaparición forzada de personas en Argentina y sus efectos sobre la representación y sus (im)posibilidades).

Y click: vuelve el crac.

Helo aqui de regreso al agujero: de nuevo en América, de vuelta a Buenos Aires, otra vez en Montevideo, otra vez con los desaparecidos que con la plaza y la ubicación y la conversión en anfitrión y la visibilizarían y... habia creído dejar atrás.

\section{DESAPARECIDOS CORRIENDO POR LAS AUTOPISTAS INTELECTUALES DEL HUMANITARISMO \\ y ya en tierras ajenas, buscando categorías para fijar el desplazamiento perpetuo.}

Solo puedo escribir esto cuando transito, cuando me deslocalizo; cachitos en un aeropuerto, otros en un seminario fuera de casa. No miento, es así. Es cuando este texto me sale, no en casa. Es también cierto que en espacios de tránsito he pasado más tiempo últimamente del que hasta hace poco hubiera pensado que era posible, pues de la mano del objeto de mis desvelos durante los últimos diez años he viajado mucho, en trayectos bastante más vastos de lo que nunca creí que mi oficio me posibilitaría. Practicándolos, me latinoamericanizo de a poco, aunque muchas veces en muchos de ellos ni pise América Latina. En Berlín, en Heidelberg, en Barcelona, Bilbao o Konstanz, en París o en Los Angeles, en Minnesota o Coimbra, y a veces por allá, en Bogotá, Buenos Aires, Santiago de Chile, Córdoba, o Montevideo... Vean un par de ejemplos: estuve en abril de 2014 en Montevideo, mi casa, pero invitado por colegas franceses que organizaron un seminario allá sobre las sociedades post-violencia; en mayo organicé con una universidad alemana otro seminario en Bilbao con colegas argentinos, y algunos europeos, que trabajan en Inglaterra, Portugal, Alemania o Francia sobre desaparición, sangre, terror; acabo de llegar de California, donde me encontré con colegas uruguayos, argentinos y norteamericanos, todos latinoamericanos, para conversar sobre todo eso... Habito un circuito grande, lleno de latinoamericanos, hablando de América latina, que no necesita pisar América Latina. Pasa el tiempo, y no hago sino sudaquizarme de más en más: grupos de estudios, colegas, activistas, redes y centros de investigación, revistas... Ilenan esa América Latina, que no tiene la consistencia que tuvo (nacional, intelectual, etc.) sino otra, menos circunscrita a viejas territorialidades, adscrita acaso a las de la diáspora (Irazuzta, 2015, en este número de Papeles del CEIC). 
En lo que a mí respecta, la condición de posibilidad de esos recorridos es un objeto que les es, y perdonará el lector el neologismo, homeomorfo: si uno -el circuito - es móvil, volátil, el objeto de estudio a cuyos lomos me he montado para recorrerlo -el desaparecido-, lo es aún más. Al desaparecido me acerqué tras dejar atrás a los vascos que aprenden a serlo y con conceptos como "parásito", "social invisible", "modalidades débiles de la identidad" (Gatti, 2007) en el equipaje. Obvio consideraciones fáciles sobre las razones por las que estudio el tema. Son tan obvias que deben estar equivocadas (Gatti, 2014). Prefiero pensar en razones más estructurantes, que tiene que ver con la identidad de esta figura y con la de los que viven en los lugares sociales que la administran. Pensándolo así, la figura - terrible, lo sé- es sin embargo teóricamente fascinante para los que estamos interesados en identidades raras: con él, el concepto mismo de identidad pierde pie y obliga a bucear en mares en los que un sociólogo suele ahogarse. Pues nada encaja: los cuerpos se separan de los nombres; las palabras se disocian de las cosas. Identidad sin cuerpo, cuerpo sin identidad, filiación quebrada, normalidad resquebrajada... Es inconsistente, escurridizo para el lenguaje de la ciencia social; como muchos otros ciudadanos convertidos en parias, fue desterrado al territorio del afuera, donde deviene un desolado, un expulsado de lo humano. No está solo: en el mundo social construido en torno a él se dan fenómenos que recuerdan a figuras no tan extrañas para el sociólogo, aunque también incómodas: refugiados, banidos, exiliadas, desplazados, precarias, fugadas, transexuales, desocupadas, iniciandas, perdidos, aprendientes... En fin, los monstruos, muchos, de la identidad y de la vida social, que reclaman atención desde un sensorio parecido al que requiere una sociología del desaparecido.

Complicado. Complicado también el sujeto colectivo que se estructura en torno a él, instalado en un duelo permanente, movido por el deseo de su propio fin, con una agencia que se construye en espacios de los que para la sociología siempre fue difícil transitar, demasiado sucios para nuestras botas. Y pese a todas esas inconsistencias el desaparecido - la categoria de "desaparecido"- ha tenido éxito y se ha transnacionalizado. Hoy, situaciones muy distintas y muy remotas son pensadas con un patrón común, el que suministra la figura del desaparecido en su variante argentina, que es la que a mí me ha ocupado.

El desaparecido que hoy triunfa mundialmente tiene un origen de coordenadas muy locales. Es ése propio de la Argentina de la dictadura militar de los años 1976-1983 y en alguna medida de las de Uruguay, Chile y parcialmente Brasil del mismo período. Con el tiempo salió de su Cono Sur natal y la acepción argentina del desaparecido y de la 
desaparición forzada se hizo referencia para la ley humanitaria internacional. A partir de ahí, será la vara de medir de todo otro resultado de prácticas de desaparición forzada de personas, sea o no el Estado el ejecutor, haya o no haya habido paradero desconocido del sujeto desaparecido, haya sido o no selectivo y sistemático el proceso de elección de víctimas del dispositivo desaparecedor, sea un individuo, un grupo étnico, una comunidad rural o un colectivo de creyentes el destinatario. Sea como sea, la definición ha tenido éxito, enorme, y el concepto de desaparecido que inventa la que la literatura de ciencias sociales argentina llama, ignoro si con ironía o por mero convencionalismo, "la última dictadura" y que luego, en 2007, refrenda la ONU, viaja de un continente a otro, de época en época, sin sufrir demasiado los desajustes que tan largos desplazamientos deberían depararle. Endurecido, el detenido-desaparecido, se ha convertido en un verdadero móvil inmutable (Latour, 1985): nació, y nació complejo, en los chupaderos argentinos y luego se ha convertido en la matriz de referencia con la que se piensan, se miden y de más en más se juzgan los múltiples casos de desaparecidos locales. Una impresionante historia de éxito y de consolidación de un objeto, que hoy, impasible, surca espacios y tiempos, rocoso, siempre igual por mucho que se desplace, sin inmutarse a pesar de las diferencias entre sus usos locales. A star is born, y es fulgurante.

¿Qué autopistas ha usado para viajar tan rápido y tan fácil? Podemos pensar que se trata de un caso más de circulación transatlántica, de otro objeto que se deslocaliza, como unas zapatillas Nike, una película japonesa, una orientación sexual, o una identidad étnica, y que en esa transnacionalización da argumentos que justifican la constitución de redes de estudio y de trabajo académico planetarias $y$, también ellas, deslocalizadas. Algo de eso hay y así ha ocurrido con las cosas de América Latina en unas cuantas variantes de los Cultural Studies: los chicano Studies, los latino Studies, los Spanish Studies, los Iberican Studies... y algunas redes que los asocian (caso de LASA, la Latin American Studies Association), han cobijado objetos como éste, el desaparecido, que ha encontrado en ellas autopistas rápidas por las que discurrir y buenas plataformas de exhibición para que los que los pensamos contemos lo que sabemos de ellos a públicos en ocasiones algo disparatados. Esa era, de hecho, mi sensación cuando en el congreso de LASA de Las Vegas en 2004 presenté lo primero que hice sobre desaparecidos; pero fue ahí también donde tuve ocasión de ver una película, Los Rubios, de Albertina Carri (2003) que marcó lo que sobre esto he podido decir en los años siguientes. Las cosas de América Latina -incluido el desaparecido transatlántico- circulan por un mundo desterritorializado con, tras ellos, miles de investigadores. 
Pobre argumento quizás, por cierto que sea, para explicar la transnacionalización de este personaje. Prefiero hacerlo con ayuda de una hipótesis más dura, que pasa por situar los desplazamientos del desaparecido dentro de un movimiento generalizado en el comienzo del Siglo XXI, el de consagración de los derechos humanos como uno de los discursos dominantes para percibir el mundo y sus variantes. Esa nueva economía moral (Fassin, 2010) que "atiende [de] una manera muy especial al sufrimiento y a la desdicha" (ibídem: 16) es ciertamente una autopista de circulación rápida para todo aquel que trabaje sobre sus asuntos. En el contexto de la construcción de un consenso global sobre lo humano, sobre su vulneración y sobre cómo reaccionar a ella, ha ganado peldaños un personaje que aunque viejo ha cobrado mucho brío en estos últimos años, la víctima, y algunas de ellas lo hacen especialmente. En esa carrera, el desaparecido ocupa buenas posiciones. No es para menos: es un no vivo, un no muerto, un no ciudadano, fue expulsado de la historia, carece de nombre y de cuerpo. Es lo humano en déficit. El contrasujeto del viejo sujeto humanista e ilustrado. Una víctima total.

Danilo Martuccelli (2015) indica que en las ciencias sociales de América Latina, tras unos años cincuenta orientados a pensar el desarrollo, unos sesenta sensibles a la dependencia, los setenta a la dictadura, los ochenta a la democracia, y los noventa a la identidad, el Siglo XXI es el de la madurez intelectual y el de la diversidad temática. Viendo algunas agendas profesionales (ALAS o LASA) no le falta razón, aunque no estaría de más explorar como una de las variantes de esa madurez la fuerte latinoamericanización de un asunto que trasciende las fronteras del continente, el del humanitarismo, en varias de sus modalidades: transiciones políticas, estudios sociales sobre la memoria, estudios sociales sobre la violencia... Así es, creo que bien cabe proponer la hipótesis de una profunda latinomericanización del humanitarismo, que si no sustituye sí acompaña a la "metanarrativa victimaria" (de Sousa Ribeiro, 2011), dominante durante el Siglo XX, el Holocausto. No es solo la inmensa cantidad de textos que sobre estas cuestiones paren las ciencias sociales del continente; ni tampoco los casi infinitos centros o grupos de investigación sobre estos asuntos; ni siquiera que algunos países (Argentina sobre todo) hayan hecho de sus políticas públicas en la materia piedras clave de su política exterior, de su "marca país". Es la creación de biografías intelectuales e investigadoras articuladas alrededor de estos asuntos y de los oficios que han auspiciado: memoriólogos, desaparecidólogos, cadavrólogos... Entre ellos estoy y con ellos viajo por el mundo. 


\section{Midnight in LAtin America. Criollos bregando CON el CONCEPTO DE PERRO, QUE LADRA Y QUE MUERDE}

Quizás el lector no necesité regresar sobre la copiosa bibliografía que piensa América Latina como una recreación de la razón. Sabemos desde Rama (1998), desde antes quizás, que en América las huestes de la razón, los educadores y los legisladores, el Estado, en fin, esa máquina, imaginaron que la suya era una tarea de instalación de jardineros: hacer crecer civilizaciones, mantenerlas y cuidarlas. Fue un trabajo tan duro en lo esencial como cualquier otro esfuerzo de ingeniería sociológica; poderoso como ellos, y es probable, por qué no, que en la cabeza de quienes lo pergeñaron fuese hasta bienintencionado. Buscaban la belleza, de cualquier manera. Modernidad en estado paroxístico, sociedad sometida a las miradas del ingeniero/jardinero, vista como "un objeto a administrar, como una colección de distintos problemas a resolver, como una naturaleza que hay que 'controlar', 'dominar', 'mejorar' o 'remodelar', como legítimo objeto de la 'ingeniería social' $y$, en general, como un jardín que hay que diseñar y conservar a la fuerza en la forma en que fue diseñado" (Bauman, 1997: 23) ¿Quién sostuvo ese sueño? Rama habla de letrados, y eso incluye: auditores, registradores de la propiedad, economistas, arquitectos, geógrafos, periodistas, abogados, notarios, escribanos, escribientes y burócratas de la administración... Pero la nómina es ampliable, y llega, cómo no, hasta los sacerdotes y hasta los científicos (Blengino, 2005). Primero trabajaron sobre la nada previa, que llenan, que ilustran; luego la colmaron de sabios; muchos se formaron en Europa, a donde viajaban para volver y a su regreso seguir con el trabajo de hacer crecer y cuidar el jardín ¿Es relevante para lo que hablo? Sí, pues el jardín necesita de jardineros y en origen eso es lo que somos los que escribimos en este número. Ahora, ¿qué estatuto tiene ahora ese jardín? ¿Dónde está? ¿Para qué se van fuera a formarse esos jardineros? Y si vuelven, ¿siguen desempeñando su misión como antes? Y si se quedan en el lugar al que fueron, ¿qué relación mantienen con el jardín originario?

De las inscripciones que representan al mundo al mapa que reúne esas inscripciones; de éstas, de nuevo al mundo, donde se entremezclan los instrumentos para cartografiar con las cartografías. En los territorios donde el plan funcionó quedó sellada la colonización de la realidad por los discursos que la piensan. En América en especial, que existe en sus mapas y en sus recreaciones. Sí, en eso pensaban los que dijeron que ahora el mapa antecede al territorio. Y el mapa se habita. Vieja cosa, lo sé. Necesito de Baudrillard para pensarla y si es por América que me muevo, de Borges. Pero no es el momento, eso ya fue. Mi idea es otra ahora y para eso necesito al Woody Allen de Midnight in Paris (Allen, 2011). En esa película, el personaje de Owen Wilson, norteamericano, 
descubre cómo hacer para atravesar el tiempo e instalarse de pleno en los momentos y lugares donde poder vivir en directo la ficción de la bohème parisina, aquella de intelectuales, pintores, escritores y cancan... Se pasea con Hemingway, que le aconseja cómo tratar a Scottt Fitzgerald, con quien coincide al poco de conocer a Picasso en casa de Gertrude Stein... Tras varios viajes a varios pasados, el mundo imaginado de la bohème se hace carne en el París actual y aunque quizás reducido a sus estereotipos, es para el personaje de Wilson, que sigue siendo un americano en París, un lugar donde estar junto a otros y otras que, como él, encontraron en ese mundo una ficción habitable, un paisaje donde estar junto a otros.

¿Es América Latina París? Creo que sí; sí al menos en la dimensión que ocupa a este monográfico de Papeles del CEIC y en lo que se refiere a cómo habito esa condición de intelectual-investigador latinoamericano desde la posición que pienso que es la mía: desde lejos, ficcionalizándola, idealizándola probablemente, pero realizándola, pues soy latinoamericano, pues investigo y publico y converso y enseño a veces en América Latina y lo hago a menudo con otros latinoamericanos fuera de allí. Así es: la ficción es tremendamente real, y en el sentido fuerte de la aportación que alguien hizo a aquella tan positivista frase de Baruch Spinoza ("El concepto de perro no ladra"). No. Pero sí muerde: esa ficción es ficción, ese paisaje sé bien que es paisaje. Pero es vivido, practicado, tiene efectos. Repito: lo habito y es eficaz.



Desde San Salvador María Santacruz habla de su tesis doctoral. La escuchan César Oré en Lima, Iñaki Robles en Getxo, Mariana Norandi en Pamplona, Pamela Colombo en París, Gabriel Gatti desde Bilbao.

hacer confortable el encuentro, y no era el de la patria desplazada sino una suerte de continente criollizado. En él, como pasa con los criollos, se

Así por ejemplo: mensualmente me reúno con quienes hacen o hicieron tesis doctorales conmigo, por Skype o Google+. No nos queda otra: María está en El Salvador, César en Perú, Mariana -que es uruguaya- en Pamplona, Pamela - que es de Buenos Aires- en París o yo mismo, junto a Iñaki e Ivana -que es también uruguaya-, nos podemos juntar físicamente en Bilbao (ver fotografía). Así también los encuentros para pensar este número de Papeles del CEIC, entre un peruano que trabaja en París, un argentino que se desplaza entre Monterrey y Bilbao y yo mismo, que se han hecho en París, en Skype, en Bilbao. Y en cada caso se activaba un paisaje imaginario para Papeles del CEIC

http://dx.doi.org/10.1387/pceic. 13066 
habla pidgin, la lengua de los que lo hablan con marcas de otros orígenes, una lengua impropia, o propia de los que tienen acento. Nacen los pidgin como lenguas de supervivencia y de negociación, no de comunidades nacionales, como lenguas de "agrupaciones provisionales" (Fabbri, 1995: 138). Son lenguas de situaciones, lenguas prácticas, que sirven para juntarse en el lugar que acoge al foráneo con otros foráneos de lenguas otras. Con ellas se construye un lugar, pequeño, no el de la Gran Lengua de una comunidad sino el chiquito de los que revolotean a su alrededor. Parásitos. A veces el pidgin gana en permanencia, y amplía también el abanico de situaciones que cubre, gana institucionalidad. Puede ser el caso entre los que componen el grupo de humanos que inquieta a los textos de este monográfico; hay síntomas de ello: los departamentos de latinoamericanistas, la Latin American Studies Association, las redes de masters en estudios latinoamericanos entre el Institut des Hautes Etudes de l'Amérique Latine y la Universidad de Salamanca, los institutos con capacidad de financiar todo esto, como el Iberoamericano en Berlín... Quizás los parásitos estén dando forma a una lengua propia y no necesiten preocuparse tanto como hasta ahora por aprehender la del anfitrión (Merklen, 2015). No me pregunten si es deseable, no lo sé.

***

Con este asunto, el que nos convoca en este monográfico, la mía al menos es una cuestión de espacios: no sé dónde ubicarme en un campo que me contiene pero que sobrepaso y me sobrepasa. Pero en este caso, el in alio loco (en otro lugar) que alimentó la fundación de las disciplinas antropológicas fomentando el viaje y la mirada distante (Affergan, 1987; Francescutti, 2015, y Castillejo, 2015; los dos últimos en este número monográfico de Papeles del (EIC) no sirve para atisbar la institucionalización de una posición, de un lugar, en un territorio intelectual. Sí sirve, sin embargo, para pensar en algunos movimientos en ese territorio, los que dibujan algunos de los que gravitan sobre él, que lo parasitan, que circulan por sus autopistas, que habian sus paisajes imaginarios. Solo eso quise proponer: que para el estado actual de esta cuestión, es hora ya de decir que algo adviene pero pronto para hacer una cartografia, aunque sí hay ya población suficiente como pensar en que, más pronto que tarde, devendrá comunidad. De momento, se vislumbra una dispersa nube de individuos flotando alrededor de sus referencias de origen (nacionales o continentales) y que, cuando habitan instancias que reconstruyen el paisaje que refleja esas referencias, las criollizan en una dirección aún imprevisible. Pero eso lo creo desde mis zapatos. Como plataforma de observación, ese zapato de 10 1/2 es corto. 


\section{REFERENCIAS CITADAS}

Affergan, F., 1987, Exotisme et altérité. Essais sur les fondements d'une critique de l'anthropologie, PUF, París.

Agier, M., 2008, Gérer les indésirables. Des camps des réfugiés au gouvernement humanitaire, Flammarion, Paris.

Allen, W., 2011, Midnight in Paris, película.

Barel, Y., 1984, "La dissidence sociale", en Actions et recherches sociales, $16 / 3$.

Bauman, Z., 1997, Legisladores e intérpretes. Sobre la modernidad, la posmodernidad y los intelectuales, Universidad Nacional de Quilmes, Buenos Aires.

Blengino, V., 2005, La zanja de la Patagonia, FCE, Buenos Aires.

Carri, A., 2003, Los rubios, película.

Castillejo, A., 2015, "Utopía y desarraigo", Papeles del CEIC, 2015/1.

De Sousa Ribeiro, A., 2011, "Memory, Identity, and Representation: The Limits of Theory and the Construction of Testimony", RCCS Annual Review, 3.

Fabbri, P., 1995, Tácticas de los signos, Gedisa, Barcelona.

Fassin, D., 2010, La raison humanitaire. Une histoire morale du temps présent, Gallimard, París.

Francescutti, P., 2015, "Una mirada casi distante", Papeles del CEIC, 2015/1.

Gatti, G., 2007, Identidades débiles, CIS, Madrid.

Gatti, G., 2014, Surviving forced disappearance in Argentina and Uruguay, Palgrave MacMillan, Nueva York.

Haraway, D. J., 1995, Ciencia, cyborgs y mujeres. La reinvención de la naturaleza, Cátedra-Universidad de Valencia, Valencia.

Irazuzta, I., 2015, "Tres vértices atlánticos: perfiles, dislocaciones y paralaje", Papeles del CEIC, 2015/1

Latour, B., 1985, "Les vues de l'esprit. Une introduction à l'anthropologie des sciences et des techniques", en Culture Technique, 14.

Martuccelli, D., 2015, "Cartografía y horizontes de la sociología sobre América Latina", Papeles del CEIC, 2015/1

Merklen, D., 2015, "En alguna parte del mundo. Montevideo, Buenos Aires, Paris", Papeles del CEIC, 2015/1. 
Rama, A., 1998, La ciudad letrada, Arca, Montevideo.

Sansot, P., 1993, "Le marginal et l'existant", en M. Amiot, I. Billiard y L. Brans (Eds.), Système et paradoxe. Autour de la pensée d'Yves Barel, Seuil, París.

Santamaría, E., 1994, "Extranjero, nada menos que una palabra mayor", en Papers, 43.

Schütz, A., 1974, Estudios sobre teoría social, Amorrortu, Buenos Aires.

Serres, M., 1995, Atlas, Cátedra, Madrid.

Serres, M., 1996, Le Tiers-Instruit, Folio, París.

Trévise, A., 1993, "Acquisition/Apprentissage/Enseignement d'une langue 2: modes d'observation, modes d'intervention", en ELA (Études de Linguistique Appliquée), 92.

Vásquez, A., 1987, “Les avatars de l'identité culturelle' étudiée chez les exilés politiques", en L'homme et la société, 1987/1. 